\title{
The behavior of stratified pools in the Wimmera River, Australia
}

\author{
Andrew W. Western, Ian C. O'Neill, Roger L. Hughes, and Jeremy B. Nolan ${ }^{1}$ \\ Department of Civil and Environmental Engineering, University of Melbourne, Parkville, Victoria, Australia
}

\begin{abstract}
Numerous inland Australian streams contain density-stratified or saline pools, which are usually located on channel bends. Saline pools consist of a layer of saline water underlying a layer of fresh water. Saline pools generally form as a result of saline groundwater seeping into the stream and collecting in scour depressions during periods of low flow. Inflows of saline river water can also collect in scour depressions. Field and laboratory investigations of saline pool mixing by overflowing fresh water reveal that mixing depends on a balance between interfacial shear and buoyancy forces acting on a thin dense layer flowing up the downstream slope of the scour depression, and on the bend sharpness. Convection associated with surface cooling also causes mixing. A model for saline pools formed by groundwater inflows and mixed by fresh overflows is proposed and applied to several saline pools in the Wimmera River.
\end{abstract}

\section{Introduction}

The acceleration of land and stream salinization, as a result of human activities, has been recognized as a significant problem in parts of Australia since early this century [Loh, 1988]. The salinization is primarily the result of a major change in the hydrologic balance caused by changes to vegetative systems and the commencement of irrigation. Replacement of deeprooted native vegetation with shallow-rooted crops and pastures since European colonization has substantially increased groundwater recharge, leading to rising water tables and consequent salinization [Ghassemi et al., 1991]. Even though the economic, environmental, and aesthetic impacts of land salinization are significant, the impact of salinization on streams may be an even greater problem in some areas, particularly in parts of Western Australia and western Victoria [Peck, 1993]. McGuckin et al. [1991] note that salt-affected rivers and streams occur throughout half of Victoria, notably on the lower-lying plains in northern and western Victoria.

Density-stratified pools form in salt-affected rivers subject to inflows of highly saline groundwater and periods of very low flow. These density-stratified pools typically consist of a layer of fresh water overlying a layer of saline water, which is usually contained within a scour hole in the stream bed. They are referred to as saline pools and are typically located on channel bends. The saline water, which is usually anoxic and acidic, is thought to be unsuitable for habitation by fish and other aerobic organisms [Anderson and Morison, 1989a, b]. Anderson and Morison [1989a, b] argue that stratified pools are an ecologically significant phenomenon because significant proportions of the river bed and banks are unavailable for use by aerobic organisms and because branches and logs on the river bed, which provide important cover and spawning and feeding sites for fish and habitat for benthic invertebrates, are inaccessible.

\footnotetext{
${ }^{1}$ Now at Mid Goulbourn Regional Water Board, Seymour, Victoria, Australia.

Copyright 1996 by the American Geophysical Union.

Paper number 96WR01336.

0043-1397/96/96WR-01336\$09.00
}

The use of environmental releases to reduce the occurrence and severity of saline pools has been suggested. However, in the past, it has been difficult to assess the effect of such releases owing to the limited understanding of saline pool behavior.

In this paper, descriptions of the Wimmera River and previous studies of its saline pools are followed by an outline of pertinent material from the extensive literature relating to density-stratified flows. This is followed by descriptions of the field and laboratory investigations of saline pools. The results of these investigations are divided into three sections: mixing, formation, and modeling of saline pools. Qualitative observations of mixing of saline pools by fresh overflows are described and used as the basis for proposing a theoretical model of the flushing process. Quantitative mixing results for fresh overflows and observations of convective mixing are also presented. Next, the streamflow conditions under which saline pools form and the rate of formation due to inflows of saline groundwater are discussed. A model of saline pool behavior is then proposed on the basis of the above results and is applied to several saline pools in the Wimmera River. Model simulations provide further insights into the behavior of saline pools. The model provides a basis for analyzing the impact of environmental flows on saline pools. This work forms part of a wider study of salinity in the Wimmera River [Western, 1994].

\section{The Wimmera River}

The Wimmera River is located in northwestern Victoria, Australia (Figure 1). In the reaches studied, the Wimmera River flows through flat alluvial plains underlain by Tertiary sediments containing saline regional aquifers [Land Conservation Council of Victoria, 1985]. The river channel is located within Quaternary river alluvium. Bed and bank materials are typically clays, silts, and fine sands [Anderson and Morison, 1989b]. The flow regime in the Wimmera River is seasonal and highly variable, and salinities are generally high. At Horsham (gauge 415200 (Figure 1), catchment area $4066 \mathrm{~km}^{2}$ ) the mean annual discharge is $139,000 \mathrm{ML}$ (34.2 $\mathrm{mm}$ of runoff). The coefficient of variation for mean annual discharge is 1.17 . Discharge in the Wimmera River downstream of Horsham is usually low or zero from November to June, and a series of rainfall-induced flow events typically occurs from July to Oc- 


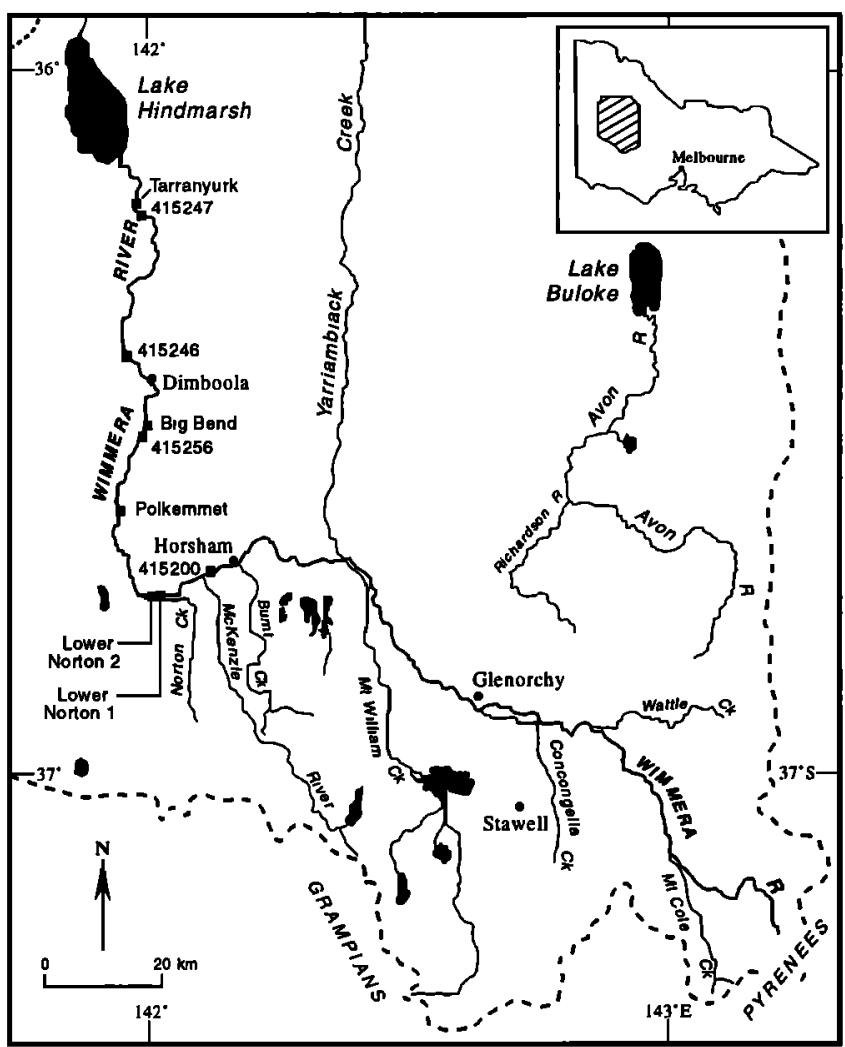

Figure 1. The Wimmera River catchment. Locations of field sites are shown.

tober; however, this seasonal pattern is variable, and low flow conditions persist throughout dry years. Diversions upstream of Horsham also affect the flow regime.

During periods of low or zero flow, the lower Wimmera River contracts to form a series of large pools separated by sections of either shallow flow or dry channel. These pools are typically 4-8 $\mathrm{m}$ deep, 30-60 $\mathrm{m}$ wide, and 1-4 km long and are more or less permanent. Each of these large pools extends over several meander bends and contains several scour depressions. Saline groundwater entering these pools collects in scour depressions, resulting in the formation of saline pools. The scour depressions are typically 1-3 m deep. Saline pools occur frequently downstream of Horsham.

\section{Study Sites}

The behavior of saline pools was studied at five sites along the Wimmera River: Lower Norton 1; Lower Norton 2; Polkemmet; Big Bend; and Tarranyurk (Figure 1). These sites are all located on bends of different sharpness. During low flow periods, depth at the sites varies between $4.5 \mathrm{~m}$ and $9 \mathrm{~m}$ and channel width varies between $30 \mathrm{~m}$ and $60 \mathrm{~m}$. The volume of the scour depressions varies between $500 \mathrm{~m}^{3}$ and $11,000 \mathrm{~m}^{3}$. This volume is that at which saline water would begin to spill from the scour depression into a neighboring scour depression. These variations are due to local geomorphic conditions.

\section{Saline Pool Processes}

Anderson and Morison [1989a, 1989b] studied saline pools in the Wimmera River. They observed that the relative cationic composition ( $\mathrm{Na} \gg \mathrm{Mg}>\mathrm{Ca}$ ) of the adjacent groundwater and the saline water in the lower layer of saline pools was similar. At most sites, saline pools consistently formed in the same locations, and the salinity and temperature of the saline layer were consistent between episodes of stratification. Seepage of saline groundwater into the stream through the stream banks was observed as well. These observations strongly indicate that the saline water in saline pools is fed by the adjacent groundwater [Anderson and Morison, 1989a, b]. Observations of gradual increases in the volume of saline water stored in saline pools during low flow periods support this hypothesis [Western, 1994].

At some locations, stratification can also result from saline river water collecting in depressions in the streambed [Anderson and Morison, 1989a, b]. Inflows of relatively fresh river water that spread over the surface of the existing water and cause stratification have also been observed in the Wimmera River [Western et al., 1993; Western, 1994].

Anderson and Morison [1989a, b] observed the effects of streamflows on saline pools in the Wimmera River. A natural flow event with an estimated peak flow of $700 \mathrm{ML} / \mathrm{d}$ at Dimboola caused partial mixing of some stratified pools, while a second event, which had a peak discharge of $3130 \mathrm{ML} / \mathrm{d}$ at Horsham, led to substantial or complete mixing of all the pools surveyed. An artificial steady flow of $50 \mathrm{ML} / \mathrm{d}$ caused little or no mixing over a 1-month period. Rates of mixing were not studied. Observations during typical mixing events (with peak discharge exceeding $1500 \mathrm{ML} / \mathrm{d}$ ) by Western [1994] indicate that saline pools are completely mixed.

Figure 2 illustrates the flows of water associated with saline pools. During periods of low flow, saline groundwater seeps into the stream and collects in depressions in the streambed. Any fresh water flowing down the river during these periods flows over the top of the saline layer. At larger stream discharges, saline water is progressively removed from the depression. Saline river water entering the pool from upstream can also contribute water to the saline layer. Convection due to surface cooling also can lead to mixing of water from the saline layer. Wind is unlikely to be a significant cause of mixing because the water surface is well sheltered by the river banks and riparian vegetation.

\section{Density Stratification and Mixing}

A brief review of the effects of density stratification is required before discussion of saline pool mixing. Turbulence and vertical mixing are suppressed by stable density stratification

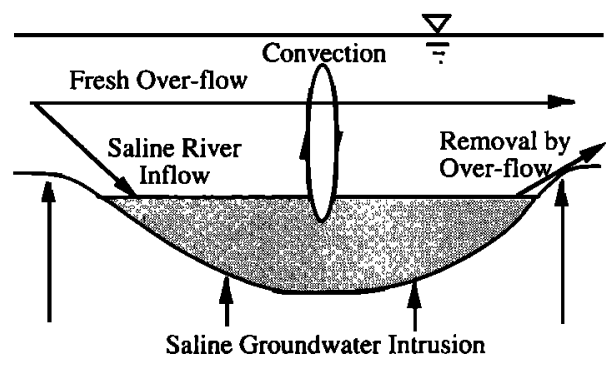

Figure 2. Formation and mixing processes associated with saline pools in the Wimmera River, Australia. Saline water is shaded. Stratification can form as a result of inflows of saline groundwater and/or saline river water. Mixing occurs as a result of flushing by fresh overflows and convection associated with surface cooling. 
[Sherman et al., 1978; Hannoun and List, 1988]. In a two-layer system such as saline pools, mixing can occur by turbulent entrainment when the velocity shear between the layers is sufficiently large. Turbulent entrainment is mixing due to turbulent eddies scouring the interface. Christodoulou [1986] summarized 12 experimental studies of turbulent entrainment and suggested that the nondimensional entrainment rate $E=$ $U_{e} / U$ is a function of the bulk Richardson number $R i_{b}=$ $g^{\prime} h / U^{2}$, where $g^{\prime}=g \Delta \rho / \rho$ is the buoyancy, $\rho$ is the density of water, $\Delta \rho$ is the density difference between the two layers, $h$ is the turbulent (upper) layer depth, $U$ is the mean turbulent layer velocity, and $U_{e}$ is the entrainment velocity, defined as the volumetric entrainment rate per unit interfacial area. Christodoulou [1986] suggested that entrainment could be predicted using (1); however, there is significant uncertainty associated with the predicted mixing rates. It should be noted that many other relationships have been proposed between entrainment and various forms of Richardson number [see Fernando, 1991].

$$
\begin{array}{cc}
E=0.07 & R i_{b}<0.01 \\
E=0.007 R i_{b}^{-1 / 2} & 0.01<R i_{b}<0.1 \\
E=0.002 R i_{b}^{-1} & 0.1<R i_{b}<10 \\
E=0.007 R i_{b}^{-3 / 2} & R i_{b}>10
\end{array}
$$

Where there is significant variation along the flow, twodimensional effects can be significant, and other mixing mechanisms should be considered. Initial field investigations [Western et al., 1993; Western, 1994] and subsequent laboratory investigations [Nolan, 1994] revealed that two-dimensional effects dominate the removal of saline water from saline pools by fresh overflows. These laboratory experiments are described later.

\section{Convective Mixing}

In many natural water bodies, transfers of shortwave and longwave radiation, sensible heat, and latent heat to and from the atmosphere occur [Fischer et al., 1979; Henderson-Sellers and Davies, 1989]. These surface energy transfers can result in either heating of the surface water layers (net energy influx) or in cooling of the water surface (net energy efflux). If surface heating is occurring, the stability of the water body will be increased, and mixing will be suppressed. However, if the surface is cooling, the density of the surface water will increase (provided the water temperature exceeds $4^{\circ} \mathrm{C}$ ), and the dense surface water tends to sink, leading to convective motions that mix the water body. Convective mixing has been recognized as an important process in both lakes and oceans [Fischer et al., 1979; Henderson-Sellers and Davies, 1989] and could potentially be important in quiescent river pools.

\section{Field and Laboratory Investigations}

\section{Field Measurements}

Vertical salinity and temperature profiles were measured at several sites in the Wimmera River over periods of $1-2$ years. These profiles were measured manually using calibrated conductivity and temperature meters at the deepest point that could be located within the scour depression. A fixed anchor was installed during mixing events so that each profile was measured at the same location. Detailed measurements were

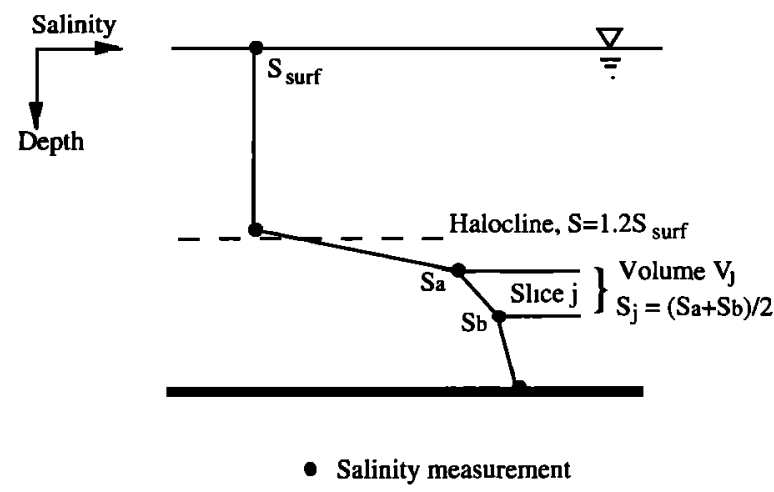

Figure 3. Procedure used to calculate the equivalent groundwater volume $V_{g w}$. The water column was divided horizontally, and the mass of additional (to that contained in the same volume of surface water) salt in each layer was calculated. This was then summed and used to calculate the volume of groundwater required to account for the salt below the halocline.

made where vertical changes in salinity or temperature were significant. During low-flow periods, the interface is relatively diffuse, and the most intensive measurement was every $0.25 \mathrm{~m}$. During higher flows the interface is sharper, and measurements were made every $0.05 \mathrm{~m}$. Significant salinity fluctuations at timescales of $10-30 \mathrm{~s}$ were observed within $0.05-0.10 \mathrm{~m}$ of the interface during mixing. These were presumably associated with interfacial waves. Where salinity and temperature were nearly uniform, the separation between the measurements was increased (maximum separation was $2 \mathrm{~m}$ ). These measurements extended from the water surface to the streambed.

Continuous salinity measurements were also made at Lower Norton 1 (0.5 m, $1.5 \mathrm{~m}$, and $2.5 \mathrm{~m}$ above the streambed), Big Bend $(0.5 \mathrm{~m}$ and $5 \mathrm{~m}$ above the streambed), and Polkemmet ( $0.5 \mathrm{~m}$ above the streambed). Data from these sensors were used to detect the time at which the interface passed the sensor during flow events and to detect convective mixing. Contour maps showing the bathymetry of each field site were constructed from surveyed cross sections.

\section{Characterization of the Stratification}

As part of the analysis, the measured salinity profiles were summarized. For data obtained during mixing events, the elevation of the interface was determined by finding the interval with the maximum salinity gradient and averaging the elevations at either end of this interval.

To study the rate at which stratification develops, the amount of stratification was quantified by calculating the equivalent volume of groundwater, $V_{g w}$, required to account for the additional salt below the halocline. To calculate $V_{g w}$, the halocline was defined as the point in the profile at which the salinity was equal to $1.2 S_{\text {surf }}$, where $S_{\text {surf }}$ is the salinity at the water surface. The factor 1.2 was chosen to ensure that essentially all the water with increased salinity was included in the calculation of $V_{g w} . V_{g w}$ is insensitive to the exact value chosen. $V_{g w}$ was calculated by dividing the water column horizontally at points where the salinity was measured (Figure 3) and using

$$
V_{g w}=\sum_{j=0}^{n} V_{J} \frac{S_{j}-S_{\text {surf }}}{S_{g w}-S_{\text {surf }}}
$$




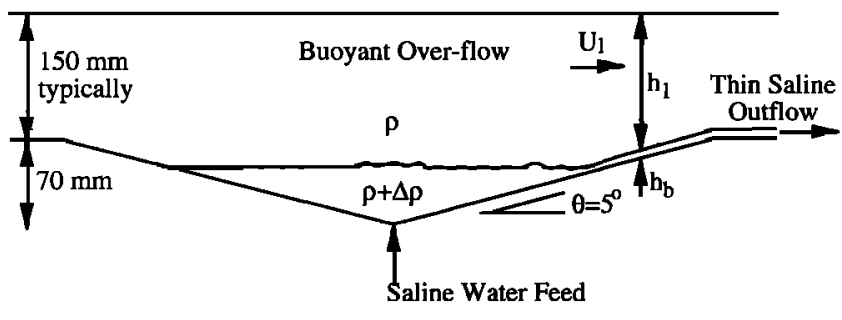

Figure 4. Flow geometry used during laboratory investigations of the flushing of saline pools. The density difference, upper layer discharge and saline water discharge were fixed and the interface elevation was allowed to adjust until equilibrium was reached.

where $V_{J}$ is the volume of slice $j, S$, is the salinity of slice $j$, and $S_{g w}$ is the salinity of the groundwater at the particular saline pool. Volumes were calculated by integrating the plan area of the scour depression over the depth of the slice, and $S_{j}$ was calculated as the mean of the measured salinity at the top and bottom of the slice. Where the stratification extended beyond the top of the scour depression, the profile was truncated at the top of the scour depression because the plan area and thus the volume above that point could not be defined and because it was then possible for saline water to drain to other scour depressions.

\section{Laboratory Experiments}

A series of laboratory experiments was conducted to investigate the mixing of saline pools by overflows of fresh water. These experiments consisted of a two-layer stratified flow with a saline lower layer and a fresh upper layer. They were conducted in a laboratory flume. The laboratory model (Figure 4) was based on the geometry of an idealized saline pool, and the velocity range was based on Froude scaling. Saline water was fed into the bottom of this depression through a diffuser at a steady rate, which was set so that the interface remained within the depression. A steady flow of fresh water was passed over the top of the saline layer. The saline water was dyed to enable flow visualization. The experiment was allowed to come to equilibrium, at which time a sharp interface between the fresh and saline water existed and the depression was partially full of saline water. The water surface elevation, interface elevation, and discharge rates for the fresh and saline water were then determined.

\section{Mixing by Overflowing Fresh Water Qualitative Observations}

The predominant removal mechanism observed during the laboratory experiments consisted of a thin layer of saline water flowing up the downstream slope of the depression and along the bed of the flume. This layer extended across the full width of the flume, and its depth was approximately $1 \mathrm{~mm}$. The interface along the majority of the depression was approximately horizontal, beginning to slope only at the downstream limit of the main stratification or at the point where the shallow flow up the downstream slope of the depression began (Figure 4). Sampling showed that the saline water flowing from the cavity was a mixture of upper and lower layer water.

Interfacial waves formed near the upstream extremity of the interface. These waves grew as they progressed along the interface and entrainment due to the breaking of these waves was observed. This entrainment increased as the waves became larger downstream and as the upper layer velocity increased or the density difference decreased. The flow up the downstream slope of the depression was continuous, and although it was steady at a sufficiently long timescale, surges resulting from interfacial waves arriving at and progressing up the downstream slope were observed on some occasions. It is possible that the partially mixed water flowing from the downstream end of the depression results from partial mixing during wavebreaking episodes. Experiments with varying end wall slopes $(\theta)$ indicate that the mixing regime described above persists until $\theta$ exceeds $20^{\circ}$ [Nolan, 1994], which is greater than the majority of scour depressions in the Wimmera River. The process whereby saline fluid is removed by interfacial shear associated with the flowing upper layer will be referred to as flushing.

\section{The Flushing Process}

The flushing process is characterized by a thin saline layer flowing up the downstream slope of the depression. A force balance can be written for this layer (equation (3) below), which is referred to as the bed layer to distinguish it from the main body of saline water in the depression. For the bed layer it is assumed that convective accelerations are zero (the top of the bed layer is parallel to the flume bed), that boundary shear stress is negligible, that steady state exists and that $\theta$ is small $(\cos \theta \approx 1)$.

$$
\frac{\tau_{1}}{\rho h_{b}}-g \frac{\partial H}{\partial x}-g^{\prime} \tan \theta=0
$$

In (3), $\tau_{t}$ is the interfacial shear stress, $h_{b}$ is the vertical depth of the bed layer, $H$ is the elevation of the water surface, and $x$ is the horizontal distance downstream. The pressure term can be estimated by combining the steady state momentum and continuity equations for the upper layer

$$
g \frac{\partial H}{\partial x}=-\left(\frac{\tau_{l}}{\rho h_{1}}+\frac{2 \tau_{w}}{\rho B}-\frac{U_{1}^{2}}{h_{1}} \frac{\partial h_{1}}{\partial x}\right)
$$

where $\tau_{w}$ is the wall shear stress, $U_{1}$ is the upper layer velocity, $h_{1}$ is the upper layer depth, and $B$ is the channel width. Substituting (4) into (3) gives

$$
\frac{\tau_{t}}{\rho h_{b}}+\frac{\tau_{t}}{\rho h_{1}}+\frac{2 \tau_{w}}{\rho B}-\frac{U_{1}^{2}}{h_{1}} \frac{\partial h_{1}}{\partial x}-g^{\prime} \tan \theta=0
$$

Now assuming that $\tau_{w}$ is of the same order as $\tau_{t}$ and noting that $h_{b} \ll h_{1}$ and that $B$ is of the same order of magnitude or larger than $h_{1}$ means that the second and third terms on the left of (5) can be ignored. Furthermore, $U_{1}^{2} / h_{1} \ll g^{\prime}$, and $\partial h_{1} / \partial x \approx \tan \theta$. Therefore (5) can be simplified to

$$
\tau_{s} / \rho h_{b}=g^{\prime} \tan \theta
$$

Equation (6) implies a local equilibrium between the interfacial shear and the buoyancy forces.

Assuming that $U_{b} \propto U_{1}$ and that $\tau_{t} \sim \rho U_{1}^{2}$, then $h_{b} \propto$ $U_{1}^{2} / g^{\prime} \tan \theta$ and

$$
Q_{b}=h_{b} U_{b} B=C_{f} \frac{U_{1}^{3} B}{g^{\prime} \tan \theta}
$$

where $C_{f}$ is a flushing coefficient and $Q_{b}$ is the volumetric flow rate in the bed layer. Equation (7) suggests that the flushing process does not depend on any externally determined length 
scale. It is noted that interfacial waves can contribute energy to the outflow, as is evidenced by surges observed in the bed layer under some conditions, and that turbulent entrainment also contributes to the removal of saline water. Other equations would be required to describe these processes, and therefore (7) is expected to hold only where the dominant source of energy contributing to the removal of saline water from the depression is interfacial shear stress acting directly on the bed layer as it flows up the downstream slope of the depression.

\section{Quantitative Observations of Flushing}

Sequences of vertical salinity profiles were measured at Lower Norton 2 on August 15 and 16, 1992, and at Tarranyurk on September 3, 1993. Examples of the salinity profiles collected at Lower Norton 2 are provided in Figure 5. Figure 6 shows the interface elevation data for Lower Norton 2. The position of the interface was determined for each measured profile, and a second-order polynomial was used to describe the variation of interface elevation over time. $Q_{b}$ was calculated by differentiating this polynomial with respect to time and multiplying by the plan area of the interface. River stage was monitored, and discharge was determined from a rating curve. $U_{1}$ was determined as the mean velocity at the point where the interface intersected the downstream slope of the scour depression. The density difference across the interface was estimated from the salinity difference over the region in which the salinity changed rapidly, $B$ was calculated as the plan area of the interface divided by the length of the interface measured along the pool thalweg. $U_{1}^{3} B / g^{\prime} \tan \theta$ was then calculated. Figure 7 shows the relationship between $Q_{b}$ and $U_{1}^{3} B / g^{\prime} \tan \theta$ for the mixing events observed at Lower Norton 2 and Tarranyurk, combined with the laboratory measurements. Field estimates of $Q_{b}$ and $U_{1}^{3} B / g^{\prime} \tan \theta$ are subject to errors of $\pm 5 \%$ and $\pm 30 \%$ respectively.

The values of the flushing coefficient in (7) determined from the field data are significantly greater than those expected on the basis of the laboratory results (Figure 7). A number of factors may contribute to this difference. There are slight dif-

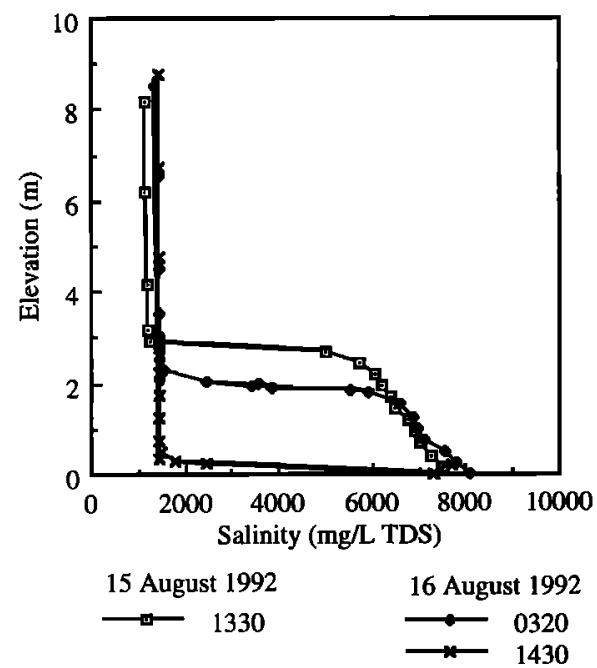

Figure 5. Typical profiles of salinity collected during the mixing event in the Wimmera River at Lower Norton 2 on August 15 and 16, 1992. Profile measurements extended to the streambed, and the saline water was completely removed by this event.

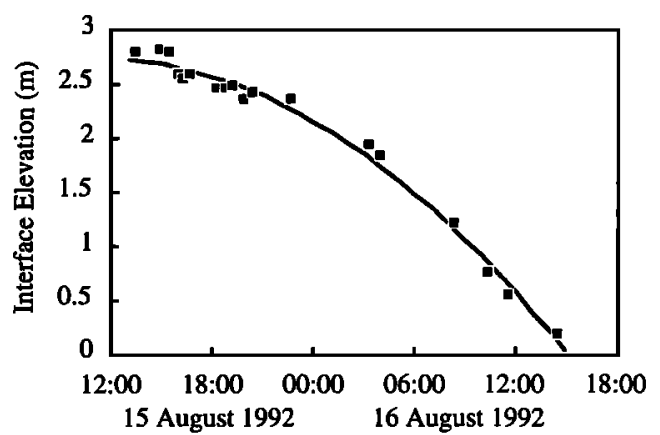

Figure 6. Variation of interface elevation with time during the mixing event in the Wimmera River at Lower Norton 2 on August 15 and 16, 1992.

ferences in the velocity scale and the estimation of $B$ used in the analyses of the field and laboratory data. In the river, $B$ varies along the length of the pool, whereas $B$ is constant in the laboratory experiments. It is difficult to assess the effect of $B$ varying along the saline pool. The lateral velocity profile is almost uniform in the laboratory, except within the boundary layers at either wall. However, in the river the lateral velocity profile is nonuniform owing to changes in depth across the channel. The difference in lateral velocity profile could account for a flushing coefficient for saline pools in the field twice that obtained in the laboratory. However, the difference between the laboratory and the field data indicates an increase in flushing by a factor of 5 . A significant difference between the laboratory and the field is that saline pools monitored in the field were located on bends, whereas the laboratory channel was straight. The hypothesis that bends affect the flushing of saline pools because of their influence on the upper layer flow is discussed in a later section.

\section{Convective Mixing}

Mixing of saline pools in the absence of significant streamflows also occurs, for example, at Big Bend between March 23 and April 27, 1994 (Figure 8). This was associated with a $3.5^{\circ} \mathrm{C}$ cooling of the water column. Continuously monitored salinity

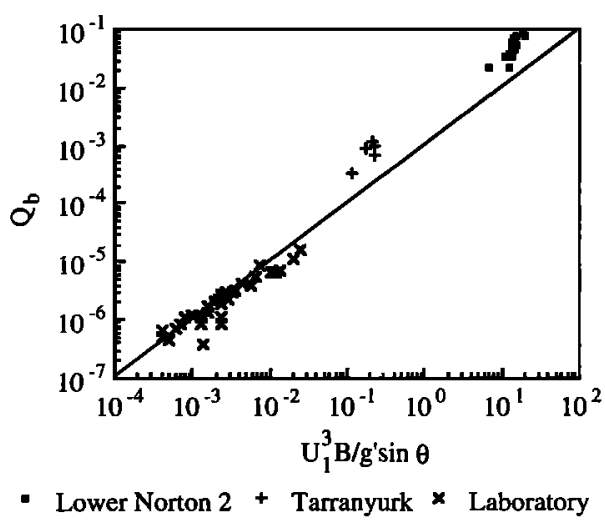

Figure 7. Variation in the rate of flushing, $Q_{b}$, with $U_{1}^{3} B / g^{\prime}$ $\tan \theta$ for mixing events in the Wimmera River at Lower Norton 2 on August 15 and 16,1992, and at Tarranyurk on September 3,1993 , and for the laboratory experiments. Field data plotting above the line shown indicate that $C_{f}$ is larger in the field than in the laboratory. 


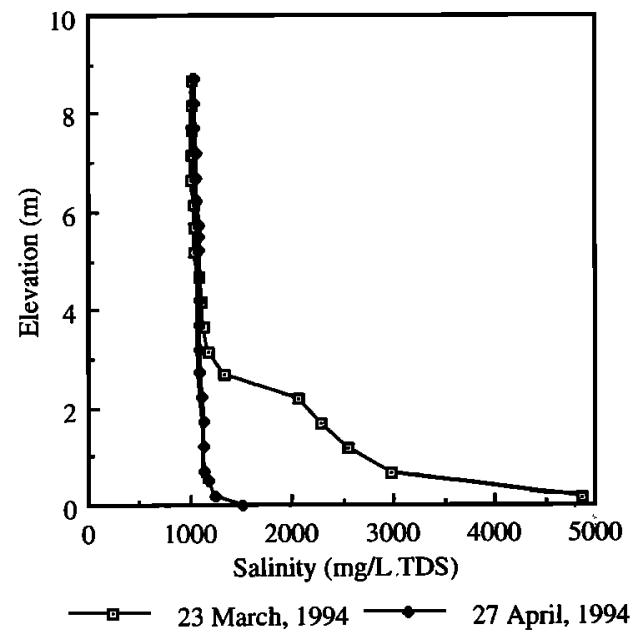

Figure 8. Vertical salinity profiles in the Wimmera River at Big Bend for March 23 and April 27, 1994. Flows during this period were low. The observed mixing is due to convection associated with surface cooling.

and temperature data at elevations of $0.5 \mathrm{~m}$ and $5 \mathrm{~m}$ in the water column (Figure 9) show that the upper part of the water column began to cool before the lower part and that significant decreases in salinity of the lower part of the water column were associated with the cooling of the lower part of the water column. The periods of cooling are associated with periods of lower daily minimum and maximum air temperatures. These data suggest mixing due to convection associated with surface cooling.

At Big Bend there is a seasonal variation of approximately $10^{\circ} \mathrm{C}$ in the water temperature. Therefore convective mixing is likely to be an annual phenomenon; however, the actual mixing would occur as a series of diurnal mixing events. During the autumn of 1993 a similar mixing event was observed at Big Bend. Also, the observed stratification at Lower Norton 2 during the autumn of 1993 was much less than expected, given the duration of low stream flow. This indicates that convective mixing may also have occurred at this site. The reader should note that convective mixing did not affect the flushing data presented above.

\section{Saline Pool Formation Due to Groundwater Inflows}

The formation of saline pools due to the inflow of saline groundwater was studied at Lower Norton 1, Lower Norton 2 , Polkemmet, and Tarranyurk. Big Bend was not used because the formation of stratification at that site is complicated by inflows of saline river water.

Salinity profiles for the four sites were examined, and the first profile indicating the presence of stratification following each high-flow event was identified. The stream discharge at this time provides a lower limit to the stream discharge at which stratification begins to develop. This analysis indicated that stratification develops when the stream discharge decreases below $200 \mathrm{ML} / \mathrm{d}, 140 \mathrm{ML} / \mathrm{d}, 330 \mathrm{ML} / \mathrm{d}$, and $300 \mathrm{ML} / \mathrm{d}$ at Lower Norton 1, Lower Norton 2, Polkemmet, and Tarranyurk, respectively. However, the flow provided for Lower Norton 2 may be artificially low owing to the small number of salinity profiles available there. The differences between sites are due to local geomorphic variations and to variation in the rate of groundwater discharge into the scour depressions.

Using estimates of the equivalent groundwater volume $V_{g w}$, the rate of formation of stratification, $\dot{V}_{g w}$, was calculated in two ways. First, following a high-flow period, the first stratified profile was identified, and it was assumed that the stratification began to develop when the stream discharge decreased below $250 \mathrm{ML} / \mathrm{d}$ and that no mixing occurred thereafter. This flow was chosen because the results given above indicate that stratification develops and therefore groundwater inflows dominate outflows due to flushing when the stream discharge drops below $250 \mathrm{ML} / \mathrm{d}$ (on average). It should be noted that the discharge (and upper layer velocity) typically drops rapidly from $250 \mathrm{ML} / \mathrm{d}$, which minimizes any errors associated with this assumption. Second, when the recorded stream flows remained low for the period between two measured profiles, $\dot{V}_{g w}$ was calculated as the difference in $V_{g w}$ divided by the time elapsed between the measurements. Formation rates were not calculated if the streamflows indicated that significant flushing may have occurred or if the scour depression was full of saline water, since saline water could then have overflowed into neighboring depressions. These estimates were used to calculate time-weighted mean formation rates, which were $10 \mathrm{~kL} / \mathrm{d}$, $21 \mathrm{~kL} / \mathrm{d}, 11 \mathrm{~kL} / \mathrm{d}$, and $8 \mathrm{~kL} / \mathrm{d}$ for Lower Norton 1, Lower Norton 2, Polkemmet, and Tarranyurk, respectively.

Variation in $\dot{V}_{g w}$ was also examined. It was found that $\dot{V}_{g w}$ increases with $V_{g w}$ at Lower Norton 2 and at Polkemmet, but not at the other two sites (Figure 10). The observations at Lower Norton 2 and Polkemmet may be due to residual mixing occurring at the end of high-flow periods, which is the time that $V_{g w}$ and $\dot{V}_{g w}$ are both small. Alternatively, a source of saline water may exist, that diffuses into the upper layer during periods of limited stratification but contributes to the water below the halocline when the depth of the stably stratified water is larger. It is also possible that saline water may begin to overflow from neighboring scour depressions during periods of
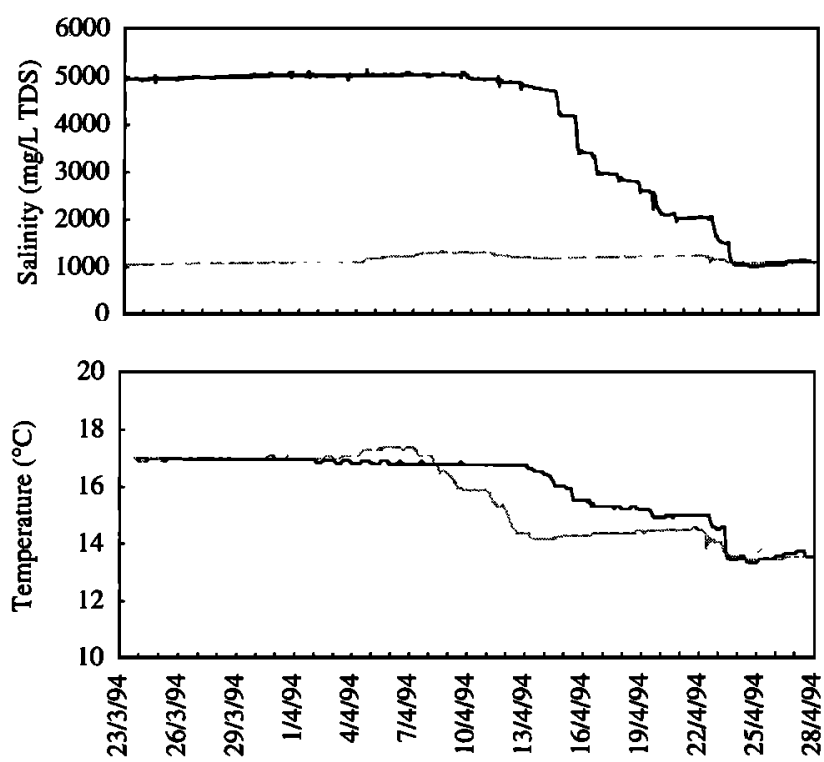

Figure 9. Variations in salinity and temperature at elevations of $0.5 \mathrm{~m}$ (solid line) and $5.0 \mathrm{~m}$ (stippled line) above the streambed for the Wimmera River at Big Bend between March 23 and April 28, 1994. Mixing due to convection associated with surface cooling occurs during the night and early morning. 
more extensive stratification. It is interesting to note that prominent bank seepage was observed adjacent to scour pools that do not become stratified. Therefore inflowing saline groundwater does not necessarily lead to the development of stratification. Whether the groundwater inflows that contribute to the stratification occur through the streambed or banks or both is unclear.

\section{Modeling of Saline Pools}

The behavior of most saline pools in the Wimmera River is dominated by groundwater intrusion and mixing due to flushing by stream flows. A simple model of these pools can be constructed by representing the stratification with a layer of fresh water and a layer of saline water and solving the continuity equation for the volume of water stored in the saline layer, $V_{s}$. Groundwater seepage contributes to this layer at a rate equal to $Q_{g w}$, and flushing leads to an outflow from the layer at the rate $Q_{b}$. The continuity equation then becomes

$$
d V_{s} / d t=Q_{g w}-Q_{b}
$$

Equation (7) was used to calculate $Q_{b}$. It was assumed that the rate at which groundwater contributes to the saline layer is independent of the amount of stratification. This allowed $Q_{g w}$ to be specified as a time series. Equation (8) was solved numerically. The bathymetry of the saline pool was calculated using tabulated values measured from contour maps of the scour depressions, while the velocity of the upper layer was calculated using a time series of stream discharge, a stagedischarge relationship, a representative cross section, and the simulated halocline elevation, which was calculated from $V_{s}$. If the scour depression becomes full at any time during the simulation, it is assumed that saline water overflows into neighboring scour depressions, and $V_{s}$ is set equal to a specified maximum value until subsequent flushing occurs. Simulation results during such periods need to be treated with caution.

The density difference was calculated in two ways. For the majority of simulations it was assumed that the respective salinities of the upper and lower layers were constant. This was incorporated in a model referred to as Salipool. The groundwater salinity was then used for the lower layer, and a typical surface water salinity was used for the upper layer. This implies that Salipool predicts the equivalent groundwater volume stored below the halocline. Errors introduced by ignoring the temporal behavior of the salinity are small because temporal fluctuations in the salinity of either layer are usually an order of magnitude smaller than the difference in salinity between the two layers. Where detailed vertical salinity profiles were available (during some mixing events), the salinity of the lower layer was calculated using the salinity profile measured at the start of the mixing event. The point in the initial salinity profile immediately below the halocline was used to represent the salinity below the interface, and the surface salinity was used to represent the salinity above the interface. This modified model is referred to as Salipool-Pr. Salipool-Pr predicts the actual volume of saline water. Comparisons of simulations indicated that the same mixing coefficient was appropriate for both Salipool and Salipool-Pr, provided the salinity of the lower layer was relatively uniform with depth.

Simulations were conducted for saline pools at Lower Norton 1, Lower Norton 2, Polkemmet, and Tarranyurk to calibrate $C_{f}$, to simulate the seasonal behavior of the saline pools, (a)

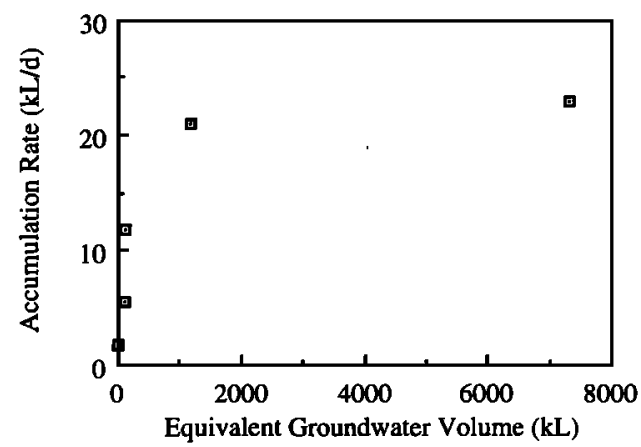

(b)

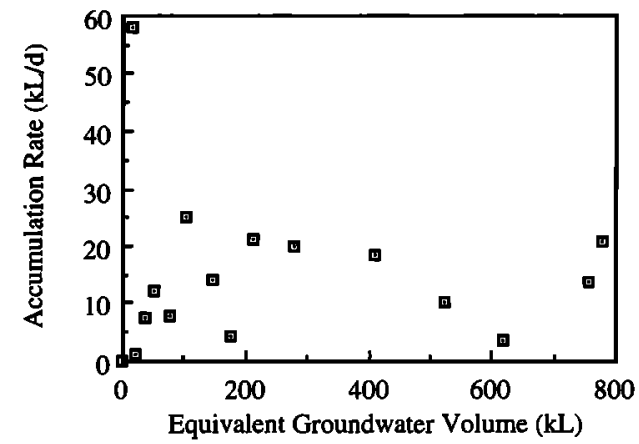

Figure 10. Variations in the rate of accumulation of saline water with the equivalent groundwater volume for the Wimmera River at (a) Lower Norton 2 and (b) Lower Norton 1.

and to assess the sensitivity of Salipool to various parameters and variables. Simulations were conducted of a flushing event at Big Bend to calibrate $C_{f}$ for that site. Other simulations were not conducted for Big Bend owing to the influence of convective mixing and inflows of saline river water at that site.

\section{Flushing Events}

To calibrate the flushing coefficient $C_{f}$ for each site and to assess Salipool's utility in predicting flushing of saline pools, either Salipool or Salipool-Pr was applied to flushing events at each of the five field sites. Several detailed vertical salinity profiles were available during flushing events at Lower Norton 2 on August 15 and 16, 1992, and at Tarranyurk on September 3,1993 . To simulate these two events, $Q_{g w}$ was set to zero, and the first measured salinity profile was used as the basis for calculating the density difference. $C_{f}$ was calibrated for each site by trial and error. Figure 11 shows the simulated and observed interface elevations at Lower Norton 2. The simulation of flushing at Tarranyurk was of similar quality to that at Lower Norton 2.

At Big Bend, vertical salinity profiles were available on August 4,1992 , which was close to the end of an extensive lowflow period, and at 1620 hours on August 16, 1992, during the final stages of a flushing event. $C_{f}$ was calibrated so that the end point of this event was correctly predicted. Since the groundwater inflow to Big Bend is small (the saline pool formed as a result of inflows of highly saline stream water prior to August 4,1992 ), $Q_{g w}$ was set to zero, and the earlier profile was used to calculate the density difference.

At Lower Norton 1 and Polkemmet, continuous salinity monitors located near the bed of the scour depression provided the end point of flushing events. These end points, to- 


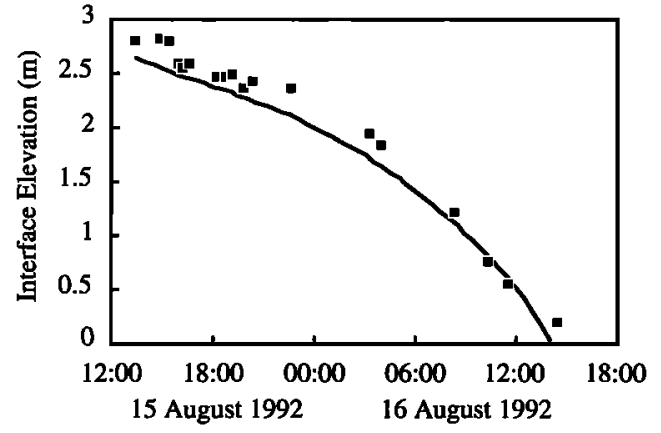

Figure 11. Simulated (line) and observed (squares) flushing for the Wimmera River at Lower Norton 2 on August 15 and 16,1992 . The density difference was calculated using the first profile measured near the start of the event.

gether with profiles measured several days before the flushing events, were used to calibrate $C_{f}$ for each site. Groundwater inflows to both Lower Norton 1 and Polkemmet are significant, and the time-averaged value of $\dot{V}_{g w}$ was used to specify $Q_{g w}$. This implies that the vertical salinity profile changes over the time between measurement of the initial salinity profile and the start of the flushing event. Therefore Salipool was used, and $V_{g w}$ calculated from the initial profile was used to set the initial value of $V_{s}$.

Calibrated values of $C_{f}$ for the five sites varied between 0.0042 and 0.043 . Values of $C_{f}$ were not validated on account of there being data for only multiple (two) flushing events at Lower Norton 1 and the fact that only the end points of the flushing were available for that site. However, at Lower Norton 1 , calibrated values of $C_{f}$ for two independent events were 0.0042 and 0.0048 , a difference of $13 \%$. Furthermore, the flushing rates predicted for the events at Lower Norton 2 and Tarranyurk were substantially correct throughout the mixing events. These results provide some support for the hypothesis that $C_{f}$ is constant for a particular site and indicate that Salipool can predict adequately the flushing of saline pools by fresh overflows.

\section{Seasonal Behavior}

The seasonal behavior of saline pools at Lower Norton 1, Lower Norton 2, Polkemmet, and Tarranyurk was simulated using Salipool. The calibrated models were used, and $Q_{g w}$ was set to the time-averaged value of $\dot{V}_{g w}$ for each site. Figure 12 compares the simulated and observed equivalent groundwater volume at Lower Norton 1 , the site with the most data available. The presence or absence of stratification is well predicted and the amount of stratification present is generally predicted to within an error of $-50 \%$ and $+100 \%$. Salipool overpredicts the amount of stratification during the middle part of 1993 at Lower Norton 1 . This is partly due to the fact that the scour depression at Lower Norton 1 fills and overflows during extended low flow periods. The calculated equivalent groundwater volume accounts only for saline water within the scour depression. Because some of the water in the scour depression will be less saline than the assumed groundwater salinity, the equivalent groundwater volume is less than the total volume of the depression, even though the depression is completely full of saline water. However, Salipool assumes that all the water in the depression has a salinity equal to the groundwater salinity. Thus neglecting saline water that has overflowed from the scour depression can account for some of the observed error. Simulations of the seasonal behavior of saline pools at the other sites are of similar quality.

The results from the simulations described above give some insight into the seasonal behavior of saline pools in the Wimmera River. The timescales involved in saline pool formation and flushing are radically different. This is expected, since flow events are the primary cause of flushing and groundwater intrusion is responsible for formation of the stratification. For saline pools under the current flow regime in the Wimmera River, the model predicts a dichotomy between low-flow periods when flushing is insignificant and flow events when groundwater inflows are insignificant.

\section{Sensitivity Analysis of Salipool}

Sensitivity analyses of Salipool were conducted for three different situations: flushing caused by a discharge increasing linearly with time, appearance of stratification during flow recessions, and development of stratification during constant moderate flows (half the discharge at which stratification initially appeared during flow recession simulations). These analyses were conducted for Lower Norton 1, Lower Norton 2, Polkemmet, and Tarranyurk. Relevant variables were increased and decreased by $20 \%$, and the sensitivity was assessed by dividing the proportional change in the predicted variable by the proportional change in the parameter. The model is described as sensitive if the magnitude of the sensitivity is greater than 1 .

It was found that Salipool is sensitive to all variables considered (stream discharge, $Q_{g w}, C_{f}, \Delta \rho$ ) during steady moderate flows. During flushing events, Salipool is insensitive to the rate of increase in stream discharge, $C_{f}$, and $\Delta \rho$. The prediction of the initial development of stratification during a flow recession is insensitive to $C_{f}, Q_{g w}$, and $\Delta \rho$. During the flushing and flow recession simulations, the behavior of the model is dominated by flushing. However, during steady, moderate flows, a balance between the rate of flushing and the groundwater inflow rate develops, resulting in the increase in the model sensitivity.

\section{Discussion}

\section{Relative Importance of Flushing and Convection}

While the importance of convective mixing compared with flushing due to flow events was not investigated in detail, the

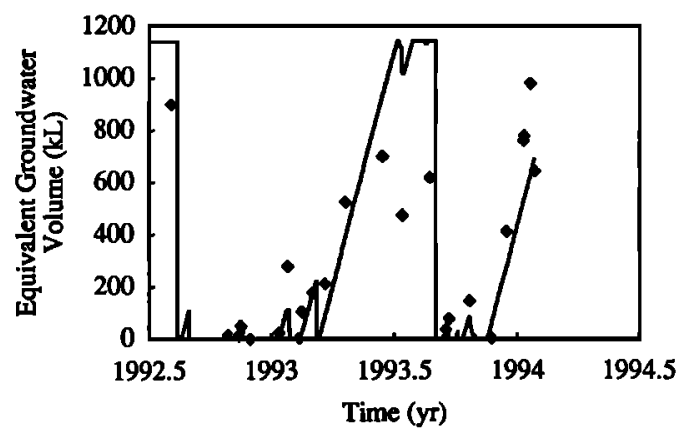

Figure 12. Simulated (line) and observed (diamonds) stratification in the Wimmera River at Lower Norton 1 for the period June 30, 1995, to February 28, 1994. The maximum volume of saline water is limited to the volume of the scour depression. 
following comments can be made. Flushing during flow events significantly smaller than the annual flood completely mixes all of the saline pools studied. Several of these flushing events would typically occur during the winter and spring months. However, convective mixing appears to be insignificant in pools with large density differences between the fresh and saline layers and in pools where there are large volumes of saline water present. Therefore it is probable that the dominant mixing process in most saline pools is flushing.

\section{Bends and Flushing}

The difference between flushing coefficients obtained in the laboratory and in the field may be due to the influence of bends. Channel bends induce secondary currents and have significant effects on the lateral and vertical velocity distributions. For a fully developed bend flow in a channel with a uniform cross section, near-bed velocities tend to increase and change direction so that they have a component towards the inner bank [Rozovskii, 1957]. Dietrich and Smith [1983] argue that in natural streams this secondary circulation is often significantly altered or eliminated by point bars, which induce a secondary transverse flow toward the outer bank where the channel is shoaling in the downstream direction. With prominent point bars this flow can extend across the inner three quarters of the channel and across the full depth of the flow [Dietrich and Smith, 1983]. Channel surveys show that the field sites do not have significant point bar development and that the most significant characteristics of the bend flows at these sites are likely to be secondary circulations rather than transverse flows. Convective accelerations can also be important in bends; however, order of magnitude analysis shows that they are unimportant in this particular case. Whatever the detailed characteristics of the bend flows, the existence of significant scour holes indicates increased levels of shear stress. Assuming that (7) is an adequate description of the flushing process, which our results confirm, the larger flushing coefficient obtained in curved (field) compared with straight (laboratory) channels is expected.

Figure 13 shows the relationship between $C_{f}$ and $D / R_{b}$, where $D$ is channel depth and $R_{b}$ is the bend radius. $D / R_{b}$ is a measure of bend sharpness. The flushing coefficient for the laboratory data is also included in Figure 13. The flushing coefficient generally increases with bend sharpness. This is consistent with the hypothesis that bends increase flushing as a result of their effect on the interfacial shear stress. Further investigation of this hypothesis and testing of the provisional curve shown is required. Nevertheless, it appears likely that the bend sharpness could provide a reasonable basis for generalizing $C_{f} D / R_{b}$ is also easily measurable, which is advantageous.

\section{Flow Regime Implications}

The flow regime of the Wimmera River results in a dichotomy between short periods of significant flushing and long periods of saline pool formation. This has several implications. On most occasions the observed formation rate will provide an accurate estimate of the rate at which groundwater contributes to the stratification. Therefore the use of the time-weighted formation rate as an estimate of $Q_{g w}$ is justified. Also, the formation and flushing components of Salipool must be calibrated and tested with data collected on different timescales. Calibration of $C_{f}$ and testing of predicted flushing requires detailed observations during short-term flushing events, while

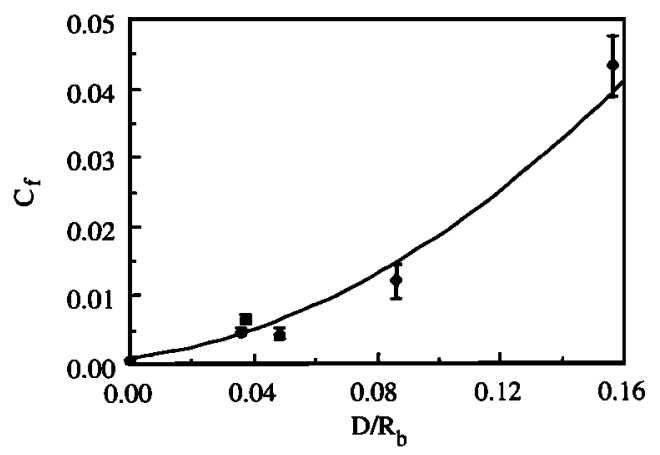

Figure 13. Variation in flushing coefficient $C_{f}$ with bend sharpness, measured as $D / R_{b} . C_{f}$ was estimated by calibrating Salipool.

observations of changes in stratification over lengthy low-flow periods are required to characterize saline pool formation.

Another implication is that data collected from the Wimmera River under the current flow regime are unlikely to be useful for directly assessing environmental flow releases aimed at limiting the impact of saline pools. Such an environmental flow requires a trade-off between consumption of water and decreasing the severity of stratification and will therefore require a balance between formation and flushing to be developed. The results of the sensitivity analysis of Salipool are also important in assessments of environmental flows. The model is sensitive to parameter values under conditions where a balance between flushing and formation is developing, but not under the current flow regime. As a consequence, model errors may be amplified with an environmental flow scenario.

\section{Conclusions}

The formation and flushing of saline pools have been studied, and a model of saline pool behavior has been developed and applied to several saline pools in the Wimmera River, Australia. Mixing of saline pools in the Wimmera River occurs as a result of removal of saline water by overflows of fresh water during flow events. The dominant mechanism by which saline water is removed from saline pools during flow events consists of a thin layer of saline water flowing up the downstream slope of the scour depression containing the saline pool. Velocity shear due to the overflowing water, and interfacial waves that have developed on the density interface, contribute the energy required to remove the saline water from the depression. The flushing process can be modeled using (7). The value of the flushing coefficient $C_{f}$ is larger for bends of greater sharpness $\left(D / R_{b}\right)$, probably as a result of enhanced shear stresses associated with the bend flows.

Convective mixing of saline pools in the Wimmera River also occurs as a result of surface cooling and is thought to be an annual phenomenon. It is likely that flushing during flow events is significantly more important than convection in mixing most saline pools in the Wimmera River.

Density-stratified pools form in the Wimmera River as a consequence of inflowing saline groundwater collecting in scour depressions and as a consequence of buoyant river water entering pools and flowing over the surface, leaving denser water in the deepest part of the pool, or collecting in the deepest part of the pool. The time-averaged rate of accumulation of saline (ground)water was quantified for four saline pools. 
Salipool, a model of saline pool behavior applicable to pools dominated by inflows of saline groundwater and flushing due to streamflows, has been developed and applied to saline pools in the Wimmera River. Salipool is able to simulate flushing during flow events and the seasonal behavior of the four saline pools to which it was applied. Sensitivity analyses showed that Salipool is insensitive to parameter and input variable values during flushing events but that the model is sensitive during periods when a balance between the inflow of groundwater and flushing from the saline pool develops. Simulations using Salipool indicate that the behavior of saline pools under the present flow regime, which is characterized by long periods of low flow interspersed with brief flow events, is characterized by a dichotomy between periods dominated by flushing and periods dominated by accumulation of groundwater.

Acknowledgments. Tom Ryan (Kaiela Fisheries Research Station, Department of Conservation and Natural Resources, Victoria) provided bathymetry data for the Polkemmet site and some of the salinity data used in the analyses. The Rural Water Corporation of Victoria made data available and provided funding. The University of Melbourne provided an Australian Postgraduate Research Award and a University of Melbourne Studentship to support the senior author. Staff and postgraduate students from the department of Civil and Environmental Engineering, University of Melbourne, assisted with field measurements. Many useful discussions were held with Tom McMahon. The reviewers are thanked for their comments, which improved this paper.

\section{References}

Anderson, J. R., and A. K. Morison, Environmental consequences of saline groundwater intrusion into the Wimmera River, Victoria, BMR J. Aust. Geol. Geophys., 11, 233-252, 1989a.

Anderson, J. R., and A. K. Morison, Environmental flow studies for the Wimmera River, Victoria, Tech. Rep. Ser., 73-78, A. Rylah Inst. for Environ. Res., Dep. of Conserv., Forests, and Lands, Victoria, $1989 \mathrm{~b}$.

Christodoulou, G. C., Interfacial mixing in stratified flows, J. Hydraul. Res., 24, 77-92, 1986.

Dietrich, W. E., and J. D. Smith, Influence of the point bar on flow through curved channels, Water Resour. Res., 19, 1173-1192, 1983.

Fernando, H. J. S., Turbulent mixing in stratified fluids, Annu. Rev. Fluid Mech., 23, 455-493, 1991.
Fischer, H. B., E. J. List, R. C. Y. Koh, J. Imberger, and N. H. Brooks, Mixing in Inland and Coastal Waters, 483 pp., Academic, San Diego, Calif., 1979.

Ghassemi, F., A. J. Jakeman, and H. A. Nix, Human induced salinisation and the use of quantitative methods, Environ. Int., 17, 581594, 1991.

Hannoun, I. A., and E. J. List, Turbulent mixing at a shear-free density interface, J. Fluid Mech., 189, 211-234, 1988.

Henderson-Sellers, B., and A. M. Davies, Thermal stratification modeling for oceans and lakes, Annu. Rev. Numer. Fluid Mech. Heat Transfer, 2, 86-156, 1989.

Land Conservation Council of Victoria, Report on the Wimmera Area, Melbourne, 1985.

Loh, I. C., An historical perspective on water quality monitoring and modelling in Australia, Civ. Eng. Trans., 30, 239-252, 1988.

McGuckin, J. T., J. R. Anderson, and R. J. Gasior, Salt affected rivers in Victoria, Tech. Rep. Ser., 118, 150 pp., A. Rylah Inst. for Environ. Res., Dep. of Conserv., Forests, and Lands, Victoria, 1991.

Nolan, J. B., Flushing of saline pools by fresh-water overflows, M. Eng. Sc. thesis, Dep. of Civ. and Environ. Eng., Univ. of Melbourne, Parkville, Victoria, Australia, 1994.

Peck, A. J., Salinity, in Land Degradation Processes in Australia, edited by G. H. McTainsh, and W. C. Boughton, pp. 234-270, Longman Cheshire, Melbourne, Victoria, Australia, 1993.

Rozovskii, I. L., Flow of Water in Bends of Open Channels, 233 pp., Inst. of Hydrol. and Hydraul. Eng., USSR Acad. of Sci., Moscow, 1957.

Sherman, F. S., J. Imberger, and G. M. Corcos, Turbulence and mixing in stably stratified waters, Annu. Rev. Fluid Mech., 10, 267-288, 1978.

Western, A. W., The behaviour of salinity and density stratified flows in the Wimmera River, Australia, Ph.D. thesis, Dep. of Civ. and Environ. Eng., Univ. of Melbourne, Parkville, Victoria, Australia, 1994.

Western, A. W., R. L. Hughes, and I. C. O'Neill, Density stratification in the Wimmera River, paper presented at Hydrology and Water Resources Symposium, Inst. Eng. Aust., Newcastle, New South Wales, Australia, June 30 to July 2, 1993.

R. L. Hughes, I. C. O'Neill, and A. W. Western, Department of Civil and Environmental Engineering, University of Melbourne, Parkville, Victoria 3052, Australia. (e-mail: western@civag.unimelb.edu.au)

J. B. Nolan, Mid Goulbourn Regional Water Board, P.O. Box 787, Seymour, Victoria 3661, Australia.

(Received December 18, 1995; revised April 12, 1996; accepted April 26, 1996.) 


\section{University Library}

\section{- M M N E R VA A gateway to Melbourne's research publications}

Minerva Access is the Institutional Repository of The University of Melbourne

Author/s:

Western, AW;ONeill, IC;Hughes, RL;Nolan, JB

Title:

The behavior of stratified pools in the Wimmera River, Australia

Date:

1996-10-01

Citation:

Western, A. W., ONeill, I. C., Hughes, R. L. \& Nolan, J. B. (1996). The behavior of stratified pools in the Wimmera River, Australia. WATER RESOURCES RESEARCH, 32 (10), pp.3197-3206. https://doi.org/10.1029/96WR01336.

Persistent Link:

http://hdl.handle.net/11343/297423 